\title{
A Case of Alopecia Areata Mimicking Trichotillomania
}

\section{${ }^{1}$ Deepti Shukla, ${ }^{2}$ Tejas Vishwanath, ${ }^{3}$ Sandip Agrawal, ${ }^{4}$ Rachita Dhurat, ${ }^{5}$ Aseem Sharma}

\begin{abstract}
Alopecia areata (AA) is a common dermatological disease characterized by patchy areas of nonscarring alopecia. Sometimes, differentiating patchy AA from trichotillomania (TTM) can be difficult. We report a case of AA mimicking TTM.
\end{abstract}

Keywords: Alopecia areata, Trichotillomania, Tulip hair.

How to cite this article: Shukla D, Vishwanath T, Agrawal S, Dhurat R, Sharma A. A Case of Alopecia Areata Mimicking Trichotillomania. Int J Dermoscop 2017;1(1):35-37.

\section{Source of support: Nil}

\section{Conflict of interest: None}

\section{INTRODUCTION}

Alopecia areata (AA) and trichotillomania (TTM) are common diseases with hair loss encountered in clinical practice. Alopecia areata is considered to be a hairspecific autoimmune disease, which typically presents with nonscarring alopecia in a circular shape showing exclamation mark hairs. ${ }^{1}$ Trichotillomania is a form of traumatic alopecia caused by an irresistible compulsion to pullout one's own hairs, classically leaving bizarreshaped area(s) of hair loss with broken hairs of different lengths. ${ }^{1}$ Trichoscopic features of AA are characteristic, however, not pathognomonic as these features can be seen in other scalp disorders also, therefore, in cases where doubt exists, an investigation, such as a scalp biopsy is required for a more accurate diagnosis. In this case report, we have described the frequency of various trichoscopic features of alopecia.

\section{CASE REPORT}

A 35-year-old woman came with complaint of area of hair loss over frontal scalp since a month. She denied any history of hair pulling. No history of any psychiatric illness was present. On examination, a well-defined

\footnotetext{
${ }^{1-3,5}$ Resident, ${ }^{4}$ Professor and Head

${ }^{1-5}$ Department of Dermatology, Lokmanya Tilak Municipal General Hospital and Lokmanya Tilak Municipal Medical College, Mumbai, Maharashtra, India

Corresponding Author: Rachita Dhurat, Professor and Head Department of Dermatology, Lokmanya Tilak Municipal General Hospital and Lokmanya Tilak Municipal Medical College Mumbai, Maharashtra, India, e-mail: rachitadhurat@yahoo.co.in
}

single patch of hair loss of $3 \times 4 \mathrm{~cm}$ was present over frontal scalp at midpartition. There was no associated erythema or scaling over patch. Few broken hairs were present over patch (Fig. 1). On trichoscopic examination of alopecia patch done by HEINE NC1 dermatoscope, tulip hairs, miniaturized hair, and few broken hair were seen (Fig. 2). Exclamation mark hair or black dots were absent. Trichogram showed tulip flowershaped hyper pigmented distal ends of hair shaft (Fig. 3). Based on clinical and trichoscopic features, differential diagnosis were kept as TTM and AA. To make a definitive diagnosis, biopsy was done from margin of alopecia patch with a $4 \mathrm{~mm}$ punch. The H\&E section showed peribulbar lymphocytic infiltrate (Figs 4 and 5). Histopathological findings confirmed the diagnosis of AA.

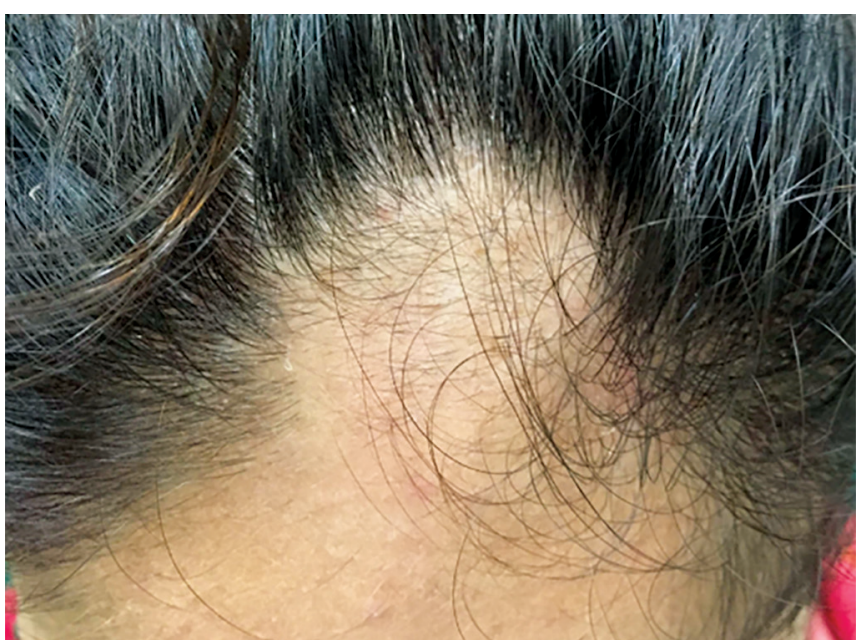

Fig. 1: A well-circumscribed patch of alopecia over frontal scalp

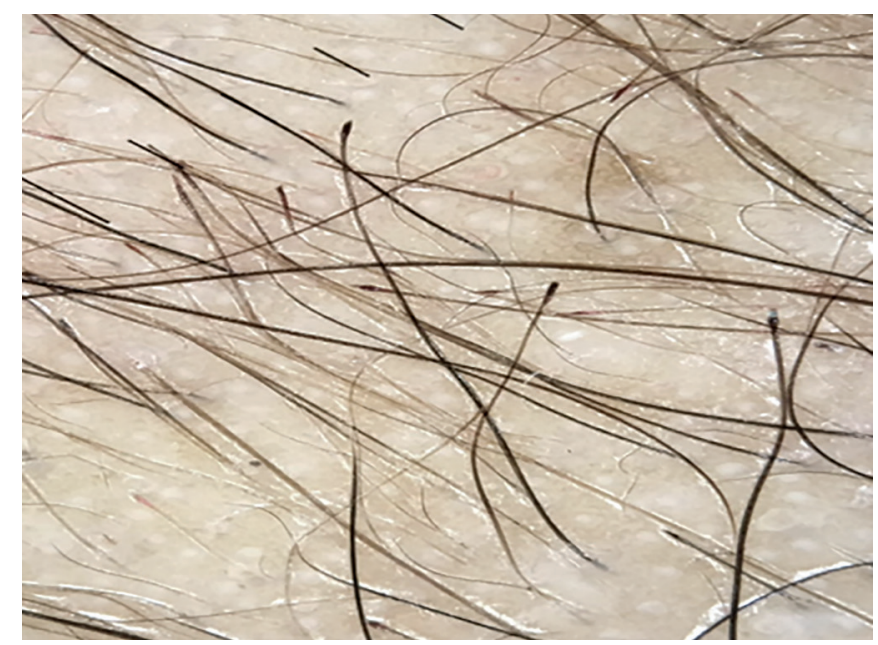

Fig. 2: Few hair with dilated hyperpigmented distal ends 


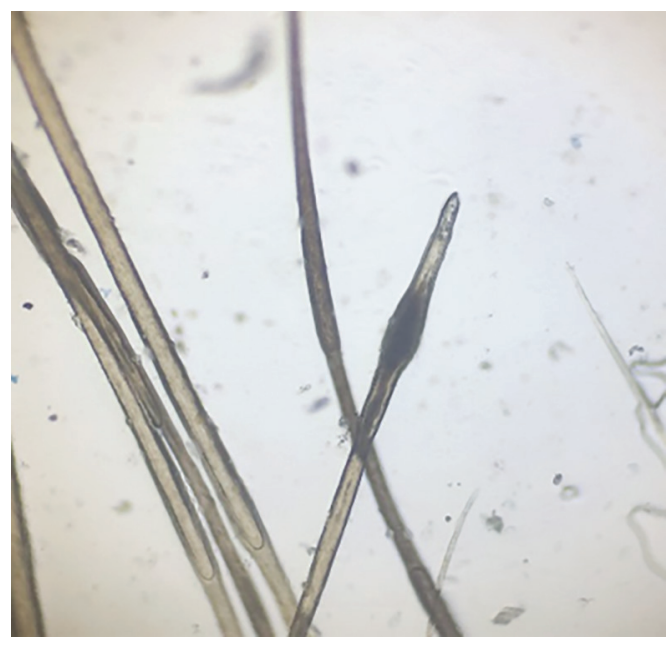

Fig. 3: Trichogram representing tulip hairs

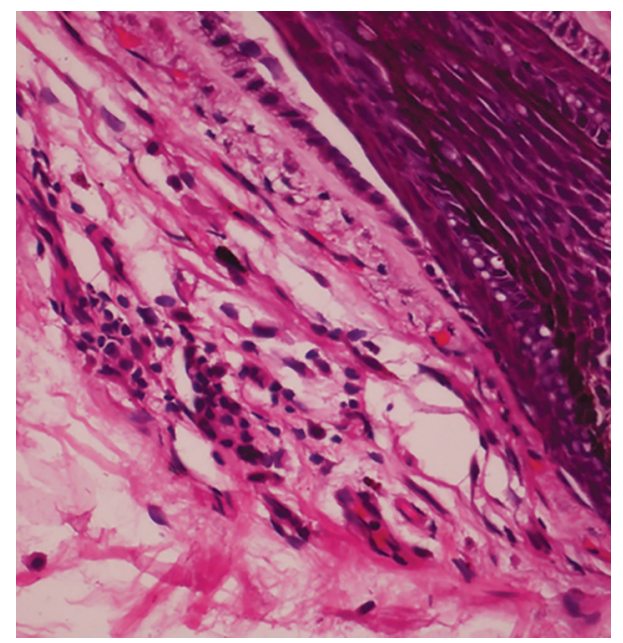

Fig. 5: The $40 \times$ lymphocytic peribulbar infiltrate

\section{DISCUSSION}

Alopecia areata and TTM are commonly encountered disorders of hair loss in clinical practice. Both conditions share similar clinical features and overlapping trichoscopic features. ${ }^{1}$

Alopecia areata generally presents as round or oval patches of alopecia, whereas in TTM patches tend to be asymmetrical, geometrical or in unusual patterns; however, round patches may also be present in TTM, making diagnostic confirmation difficult. ${ }^{2}$ The hair pull test is a useful semiotic element, which, if negative, favors a diagnosis of TTM. In AA, it is positive, particularly along the edges of patches in active disease. ${ }^{2}$

Trichoscopic features frequently observed in AA are:

- Yellow dots (empty follicles with keratin plugging) $)^{1,3,4,5}$

- Exclamation mark hairs and tapered hairs (normallooking hairs with tapering at the proximal end $)^{1,2}$

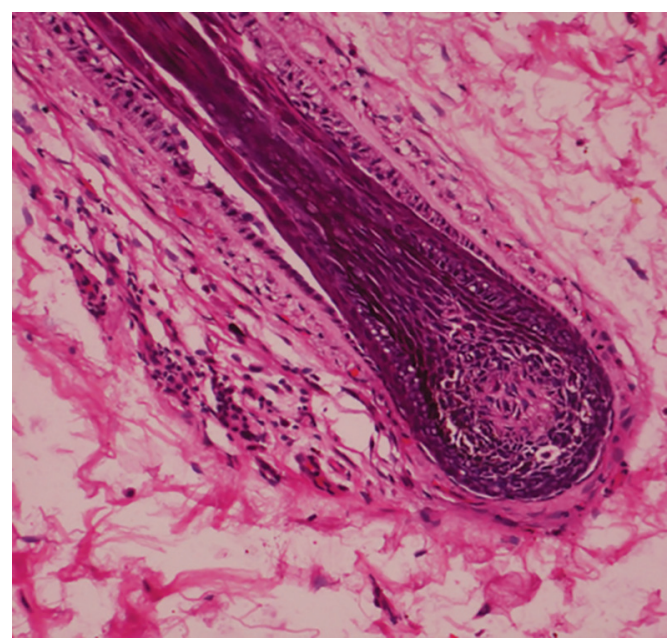

Fig. 4: The 10x peribulbar infiltrate

- Clustered short vellus hairs ${ }^{1,3,5}$

- Nonpigmented vellus hair ${ }^{1}$

- Angulated hair is a novel term introduced to describe fractured hairs forming a sharp angle along the hair shaft, regardless of the amount of fracture sites. ${ }^{1}$

Common trichoscopic signs of TTM:

- Tulip hairs are short and have darker, tulip flowershaped ends. These hairs are characteristic for TTM, however, may also be observed in AA. These are hairs in which pulling caused a diagonal fracture. ${ }^{6}$

- Broken hairs, which show extreme variability in length and morphology. 1,6

- Coiled hairs occur in response to a pulling force; a hair shaft fractures and the remaining, distal part, which is fixed to the scalp, may contract and coil. This produces coiled hairs, which are irregular in shape and frequently have features of trichoptilosis (split ends)., ${ }^{2,6}$

- Flame hair is a type of proximal hair residue, which remains attached to the scalp after pulling anagen hair. ${ }^{6}$

- $V$ sign: When two hairs emerging from one follicular opening are broken at equal level, the $\mathrm{V}$ sign is created. Partial coiling of the distal part of fractured hairs results in a hook-like appearance (also highly characteristic for TTM.) ${ }^{6}$

- Hair powder: In TTM, hair shafts may be totally damaged by mechanical manipulation and only sprinkled "hair powder" is visible. ${ }^{6}$

Exclamation mark hairs and tapered hairs have been widely believed to be characteristic for AA;1,3,7 nevertheless, these features have been reported in TTM, traction alopecia, and postchemotherapy alopecia. ${ }^{6,7}$ In a study by Khunkhet et al, exclamation mark hairs were demonstrated in $26 \%$ of the TTM patients. ${ }^{1}$ In TTM, exclamation mark hairs more often tended to have a flat distal end and a pigmented proximal end. In AA, exclamation mark hairs 
more commonly had an uneven, ragged, distal end, and a hypopigmented proximal end. ${ }^{4}$ However, both types of exclamation mark hairs can be observed in both diseases. Angulated hair is a novel term to describe fractured hairs forming a sharp angle along the hair shaft. ${ }^{1}$ In a study by Khunkhet et al, angulated hairs were not seen in any patients with TTM; therefore, it is suggested to be the most specific feature of AA. Nonpigmented vellus hairs have been reported to be a characteristic feature of AA. However, nonpigmented vellus hairs were observed in TTM cases also in a case study by Khunkhet et al. ${ }^{2}$ Broken hairs of different lengths, trichoptilosis, $\mathrm{V}$ sign (two broken hairs at the same length emerging from the same follicle) are related to mechanical trauma, and hairshaft fractures from shearing force. These features are seen in both TTM and AA. ${ }^{1,2,4}$ Flame hair sign is also related to mechanical trauma and previously it was considered as an exclusive feature of TTM, ${ }^{1}$ however, this notion was later disapproved by Miteva and Tosti. ${ }^{5}$ Tulip hairs are short hairs with darker, tulip flower-shaped ends. These hairs develop when a hair shaft fractures diagonally. They are characteristic for TTM, however, may be also seen in AA. ${ }^{1}$ In a study by Rakowaska et al, tulip hairs were seen in TTM $(48 \%)$ and $10 \%$ of AA. ${ }^{4}$
As AA and TTM have overlapping features on trichoscopy, it is of paramount importance to analyze various trichoscopic findings together with histopatholgical examination to establish the diagnosis.

\section{REFERENCES}

1. Khunkhet S, Vachiramon V, Suchonwanit P. Trichoscopic clues for diagnosis of alopecia areata and trichotillomania in Asians. Int J Dermatol 2017 Feb;56(2):161-165.

2. Abraham LS, Torres FN, Azulay-Abulafia L. Dermoscopic clues to distinguish trichotillomania from patchy alopecia areata. An Bras Dermatol 2010 Sep-Oct;85(5):723-726.

3. Mane M, Nath AK, Thappa DM. Utility of dermoscopy in alopecia areata. Indian J Dermatol 2011 Jul;56(4):407-411.

4. Miteva M, Tosti A. Hair and scalp dermatoscopy. J Am Acad Dermatol 2012 Nov;67(5):1040-1048.

5. Inui S, Nakajima T, Nakagawa K, Itami S. Clinical significance of dermoscopy in alopecia areata: analysis of 300 cases. Int J Dermatol 2008 Jul;47(7):688-693.

6. Rakowska A, Slowinska M, Olszewska M, Rudnicka L. New trichoscopy findings in trichotillomania: flame hairs, V-sign, hook hairs, hair powder, tulip hairs. Acta Derm Venereol 2014 May;94(3):303-306.

7. Tosti A, Whiting D, Iorizzo M, Pazzaglia M, Misciali C, Vincenzi C, Micali G. The role of scalp dermoscopy in the diagnosis of alopecia areata incognita. J Am Acad Dermatol 2008 Jul;59(1):64-67. 